\title{
Syphilitic aortic aneurysm: A rare case of tracheomalacia
}

\author{
Davide Pacini, MD, ${ }^{\text {a }}$ Sandro Mattioli, MD, ${ }^{\mathrm{b}}$ Massimo P. Di Simone, MD, ${ }^{\mathrm{b}}$ \\ Federico Ranocchi, MD, ${ }^{a}$ Giovanni Grillone, MD, ${ }^{c}$ Roberto Di Bartolomeo, MD, ${ }^{a}$ \\ and Angelo Pierangeli, MD, ${ }^{a}$ Bologna, Italy
}

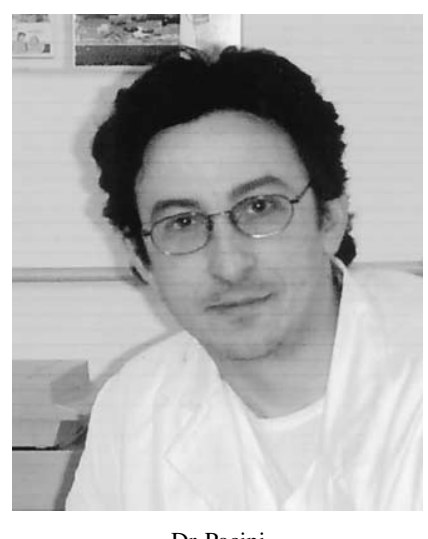

Dr Pacini

T racheomalacia, often secondary to congenital aortic arch abnormalities, can be caused by external compression of mediastinal mass, but its association with chronic aneurysms has not been previously reported. ${ }^{1}$ We present a case of severe respiratory insufficiency due to tracheomalacia. Main airway obstruction occurred immediately after aortic arch repair for luetic aneurysm and was treated successfully with temporary tracheobronchial stenting.

\section{Clinical Summary}

A 58-year-old man was referred to our hospital because of hoarseness, dysphagia, and dyspnea on exertion. He was a past heavy smoker and had no significant medical history except for a venereal infection in youth.

Chest radiography revealed a large superior mediastinal mass extending posteriorly, with dislocation and compression of the trachea and both main bronchi (Figure 1, A). On computed tomography (CT) scan, the mass was recognized as a saccular aortic arch aneurysm and measured $7.0 \mathrm{~cm}$ in maximal diameter (Figure 1, $B$ ). Respiratory function tests revealed moderate chronic obstructive pulmonary disease (forced expiratory volume in 1 second, $1.91 \mathrm{~L}$, $64 \%$; and vital capacity $3.3 \mathrm{~L}, 88 \%$ ). Serologic testing for syphilis (enzyme immunoassay) was positive.

The patient was easily intubated with an 8-mm tracheal tube. After median sternotomy, standard cardiopulmonary bypass (CPB) at moderate hypothermia was established. The aneurysm was completely located on the back wall of the aortic arch and it was not visible from the surgeon's view. A limited aortic arch replace-

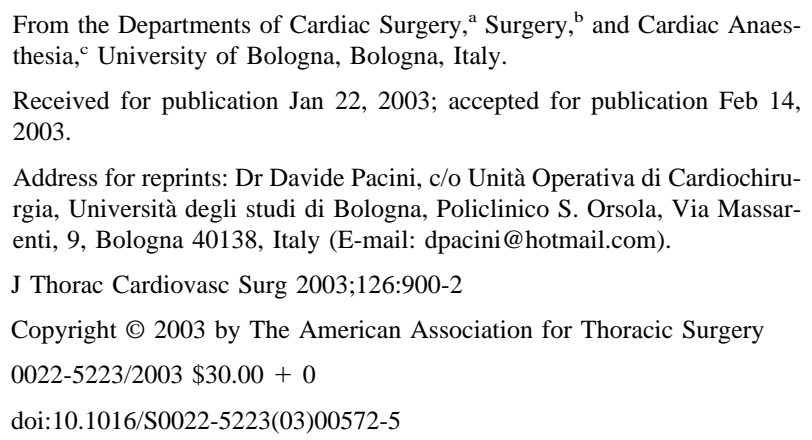

ment between left carotid artery and aortic isthmus with left subclavian artery reimplantation was performed during moderate hypothermic circulatory arrest and antegrade cerebral perfusion. During the sternum closure, a severe desaturation and an increase in airway resistance occurred. Bronchoscopy showed the expiratory collapse of the distal trachea and both main bronchi. The tracheal tube was replaced by a left-sided number 39 , doublelumen tube. Since then ventilation and blood gasses remained satisfactory. Twenty hours later, a 14-mm Y silicone stent (Hood Laboratories, Pembroke, Mass) was endoscopically inserted, and the patient was slowly weaned from mechanical ventilation. Fortyeight hours later, the patient had to be reintubated; bronchoscopy showed the collapse of the trachea above the edge of the $\mathrm{Y}$ silicone stent. On postoperative day 11, a 14-mm TY Westaby silicone stent (Hood Laboratories) was inserted under peripheral CPB to control oxygenation during the endoscopic maneuver. Afterward, the postoperative course was complicated by pneumonia and renal insufficiency recovered before discharge. The patient was transferred to a medical ward on postoperative day 39 .

The microscopic examination of the aneurismal wall revealed the characteristic changes of syphilis: medial necrosis with inflammatory infiltration, consisting of lymphocytes and plasma cells, and severe atherosclerotic degeneration.

After 6 months, the T-Y tube was successfully removed and the trachea and main bronchi were well stabilized as shown by tracheobroncoscopy and CT scan (Figure 2, $A$ and $B$ ). The patient had granulation tissue in the main left bronchus causing partial obstruction, which was successfully treated by laser therapy.

\section{Discussion}

Cardiovascular syphilis, once a relatively common disorder, has declined in incidence with the advent of antibiotic therapy, ${ }^{2}$ although in some countries recently there has been a rapid increase of this infective disease. ${ }^{3}$

Luetic aortitis is the most prevalent form of cardiovascular syphilis and produces severe destructive changes in the aortic wall. Aortic aneurysms are a common manifestation of aortitis and are typically saccular, although fusiform dilatations occur as well. Approximately $50 \%$ of aneurysms occur in the ascending aorta, 

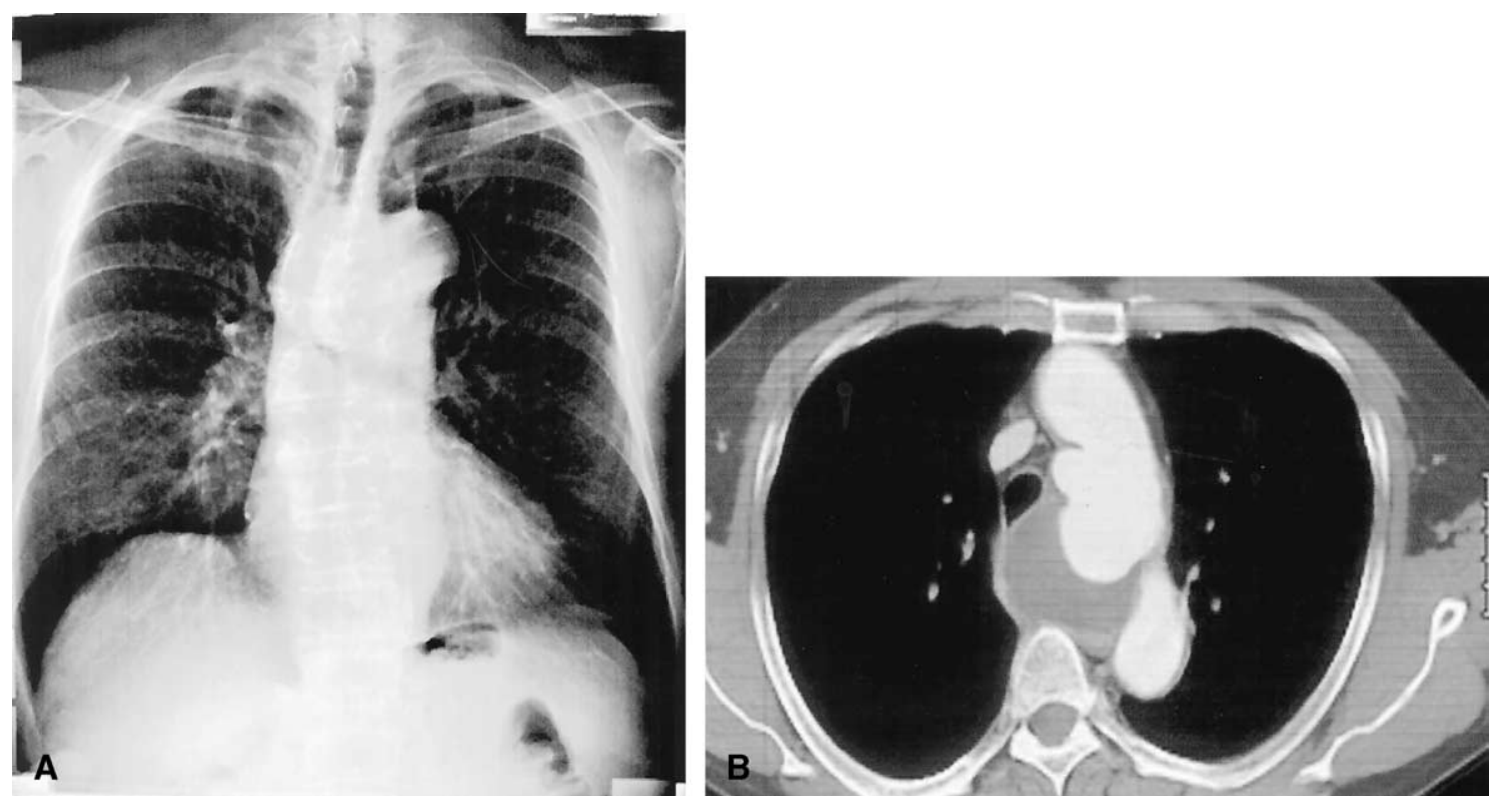

Figure 1. A, Chest radiograph (posteroanterior view) revealing a round mediastinal mass ("eggshell" pattern) that compresses the trachea and the main bronchi. B, CT scan showing an aneurysm of the aortic arch extending posteriorly. The trachea is compressed and displaced to the right side.
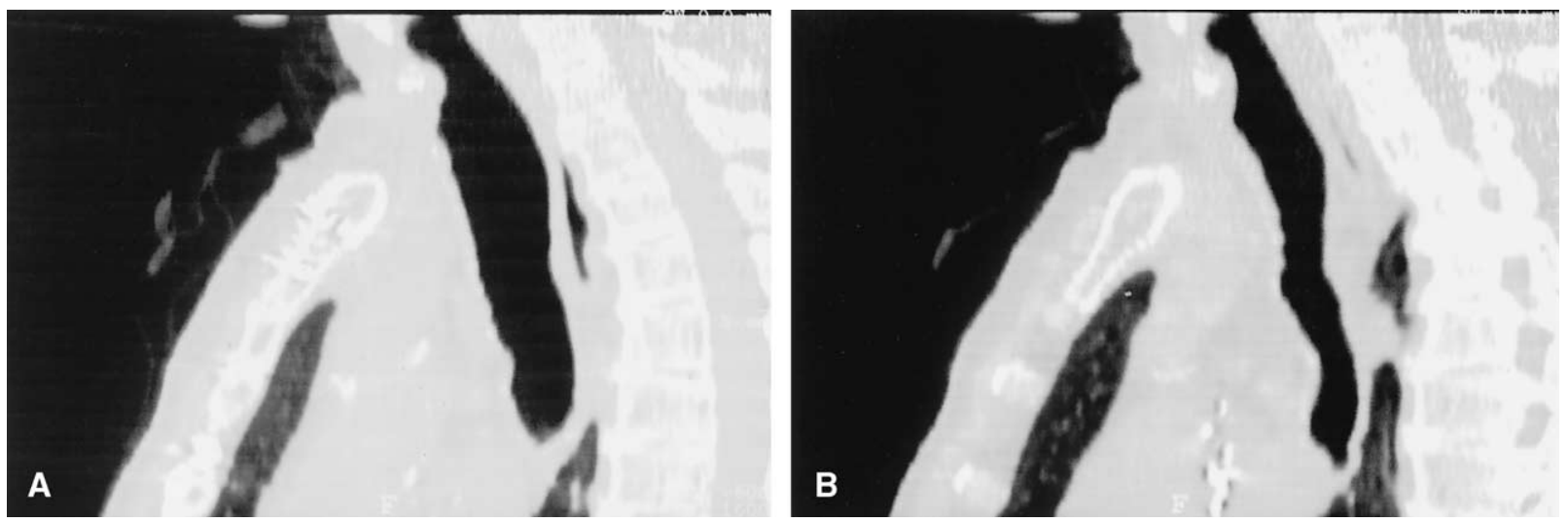

Figure 2. Multiplanar reconstruction, sagittal plain, dual-phase helical CT. A, Inspirium. B, Expirium. Final result with good stabilization of the trachea after removal of the T-Y tube.

whereas the transverse aortic arch is involved in almost $30 \%$ to $40 \%$ of the cases. ${ }^{2}$ The aneurysm in our patient involved the back wall of the transverse arch with a posterior expansion and direct compression of the trachea and both bronchi.

Tracheomalacia can be congenital and sometime is associated with congenital (or acquired) aortic arch abnormalities. The acquired form of tracheomalacia may be secondary to chronic external compression by mediastinal mass, but no case of chronic aortic arch aneurysm has been reported in the English literature. ${ }^{1}$

We believe that the particular location of the aneurysm, with a posterior expansion and the direct long-standing compression (more than 30 years) of the trachea, was the cause of the severe tracheomalacia that occurred in the reported case.
The treatment of such tracheal lesions includes direct or staged repair and reconstruction. However, sometimes these methods are unavailing, such in the case of postoperative tracheomalacia, which is a life-threatening condition. In these cases the silicon $\mathrm{T}$ or $\mathrm{T}-\mathrm{Y}$ tube may be used as a safe alternative. ${ }^{4}$ Moreover, silicon has been found to be a relatively nonirritating substance and it can be used long term in the human body. ${ }^{5}$

In cases of limited granulation tissue formation, which in the past always required removal of the tube, laser treatment now provides a good resolution.

In conclusion, we point out that tracheomalacia can occur in cases of aortic arch aneurysm with a posterior expansion and a long-standing compression of the tracheobronchial tree. Even 
though suggestive, a relationship between tracheomalacia and luetic etiology of the aneurysm cannot be established. The endoscopic treatment with a silicon $\mathrm{T}$ or $\mathrm{T}-\mathrm{Y}$ tube can be effective in resolving this lesion.

\section{References}

1. Maddans M, Pearson FG. Tracheomalacia. In: Pearson FG, editor. Thoracic surgery. New York: Churchill Livingstone; 2002. p. 272-6.
2. Jackman JD Jr, Radolf JD. Cardiovascular syphilis. Am J Med. 1987; $87: 425-33$.

3. Tichonova L, Borisenko K, Ward H, Meheus A, Gromyko A, Renton A. Epidemics of syphilis in the Russian federation: trends, origins, and priorities for control. Lancet. 1997;350:210-3.

4. Cooper JD, Todd TRJ, Ilves R, Pearson FG. Use of the silicone tracheal T-tube for the management of complex tracheal injury. $J$ Thorac Cardiovasc Surg. 1981;82:559-68.

5. Gaissert HA, Grillo HC, Mathisen DJ, Wain JC. Temporary and permanent restoration continuity with tracheal T-tube. $J$ Thorac Cardiovasc Surg. 1994;107:600-6.

\section{Bronchioloalveolar carcinoma arising from a congenital cystic adenomatoid malformation in an adolescent: The first case report from the Orient}

Manabu Sudou, MD, ${ }^{a}$ Kazuro Sugi, MD, and Tomoyuki Murakami, MD, ${ }^{\text {b }}$ Yamaguchi, Japan

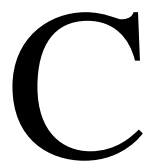

ongenital cystic adenomatoid malformation (CCAM) is an uncommon developmental abnormality of the lung that usually presents in the neonatal period. However, late-onset (over the age of 6 months) CCAM accounts for as much as $17 \%$ of all CCAM cases. Lung cancer arising in CCAM is very rare. Here we report the first case from the Orient of late-onset CCAM associated with lung cancer.

\section{Clinical Summary}

A 17-year-old man was known to have an abnormality on chest radiographs from 10 years earlier. Recently, he had dyspnea on exertion and was diagnosed as having progressive lobar emphysema of the left lower lobe. Chest radiographs showed a lucent area in the lower left lung field and the mediastinum was shifted to the right side (Figure 1). Chest computed tomography showed that the left lower lobe was occupied by huge cystic lesions with no obvious solid component (Figure 2). The patient underwent videoassisted thoracoscopic left lower lobectomy. Macroscopically, multiple cystic lesions were found in the left lower lobe and there was no evidence of a solid tumor. Microscopically, there was an excess of expanded bronchioles and a thick smooth muscle layer in the terminal respiratory structures (Figure 3), and the walls of the cysts were lined by ciliated or columnar cells. These findings were consistent with a diagnosis of type I CCAM according to Stocker's

\footnotetext{
From the Departments of Surgery ${ }^{\mathrm{a}}$ and Clinical Research, ${ }^{\mathrm{b}}$ National Sanyo Hospital, Yamaguchi, Japan.

Received for publication Nov 8, 2002; accepted for publication Jan 7, 2003

Address for reprints: Kazuro Sugi, Higashikiwa 685, Ube, Yamaguchi 755-0241, Japan (E-mail: ksugi@ sanyou.hosp.go.jp).

J Thorac Cardiovasc Surg 2003;126:902-3

Copyright $\odot 2003$ by The American Association for Thoracic Surgery $0022-5223 / 2003 \$ 30.00+0$

doi:10.1016/S0022-5223(03)00397-0
}

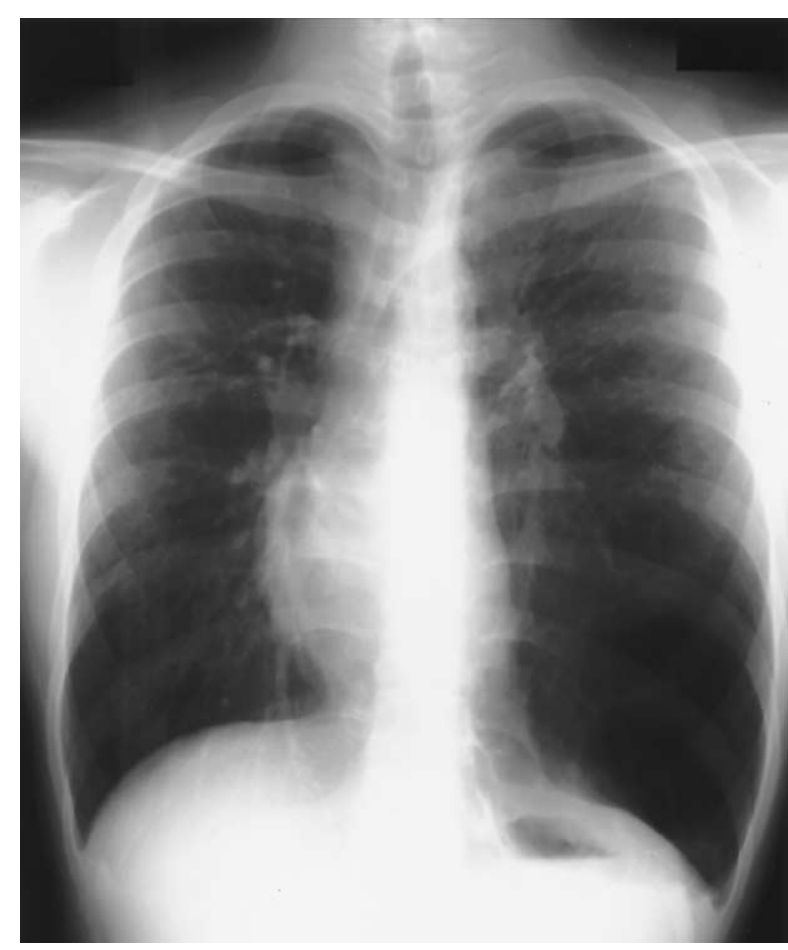

Figure 1. Chest radiograph shows a lucent area in the lower left lung field and the mediastinum shifted to the right side.

classification. In addition, a well-differentiated bronchioloalveolar carcinoma $(3 \times 1 \mathrm{~mm})$ was detected near the hilar side of the cystic lesions without lymphatic or pleural involvement (Figure 4).

The postoperative course was uneventful and the patient was discharged on the 8th postoperative day. He is currently doing well and has no evidence of recurrence or metastasis at 3 months after the operation. 